\title{
Interactive comment on "Haze pollution in winter and summer in Zibo, a heavily industrialized city neighboring the Jin-Jin-Ji area of China: source, formation, and implications" by Hui Li et al.
}

\section{Anonymous Referee \#1}

Received and published: 4 March 2018

The paper reported the field measurement results at an urban site in industrialized cities in North China Plain, where particle pollution is a severe problem. The authors identified several episodic events in both winter and summer, reported the chemical species and sources of PM2.5 particles, and proposed the formation mechanisms of the secondary species, especially the secondary inorganic species. Overall, the manuscript is well written. Detailed analyses of the formation of haze events, especially during different seasons over the year, are helpful for pollution control. There are a few points need to be addressed before publishing. 
1, Line 111: what do the authors mean that "the final hourly ammonium was corrected with the offline data"? Please provide more information on the data correction; and is it reliable to do so? What are the uncertainties?

2, Line 154: Please provide more details on the definition of haze and non-haze days. How to categorize the haze and non-haze days?

3, Line 245-246: I'm not sure if $\mathrm{CO}$ can be used as an indicator since the author also mentioned in the introduction that $\mathrm{CO}$ is largely emitted from coal combustion. And in winter, the emission is probably larger due to heating activities. Dilution or concentration resulted from the change of $\mathrm{MHL}$ is not the only reason for the variation of $\mathrm{CO}$. For example, as shown in Figure 4, CO increased largely from 00:00 to 8:00 am but the pressure was roughly stable. MLH does not seem to be the reason. Are there any sources of $\mathrm{CO}$ during the night?

4, Line 251: $\mathrm{RH}$ seems to peak at 9:00am instead of 11:00am as shown in Figure 4 a. Please elaborate more on why photochemical and heterogeneous reactions contributed to the formation of secondary species? How the conclusion is reached?

5, (1) Lin 279- 280: As the authors state, EC is a primary pollutant; hence, it is closely related to primary emission. Primary emission can be very different during a day, i.e. increased EC emission during traffic rush hours, which will certainly result in variations. Similar to CO, the authors cannot assume concentration of EC is more sensitive to MLH. (2) Line 310: Ditto. Please provide more information on whether using EC as an indicator for dilution effect is appropriate.

6, Line 337-338: Precipitation would also decrease the concentration of other species such as EC. Is precipitation data available to support that the decrease of sulfate is due to the scavenging effect?

7, Line 372-374: "Hydrolysis of N2O5 (the production of $\mathrm{O} 3$ and NO2) occurs mainly at night, thus the lower concentration of $\mathrm{O} 3$ may be a result of its contribution to $\mathrm{N} 2 \mathrm{O} 5$,

Printer-friendly version

Discussion paper
Interactive

comment 
that is, HNO3 at night (Pathak et al., 2011b). " The conclusion is a way too speculative. The reaction has to be very significant to be the sink for O3. If so, this would conflict with the conclusion by the authors later that particles phase nitrate is formed through the gas-particle partitioning of the gas-phase formed ammonium nitrate.

8, line 548-549: It is natural to expect that air masses from coastal area is cleaner than from other places. The authors attribute the high OM concentration in $\mathrm{S} 1$ to biomass burning. But from the fire spots data, it seems more fire spots were shown along cluster 4 , yet organic concentration in S4 is lower than that in S1. Is there any other evidence, such as metal ions or organic tracers from biomass burning to support that cluster 1 is affected by biomass activities? Coincidently, another coastal cluster, cluster 5 , also results in high OM concentration compared with cluster 4 although cluster 4 has a higher wind speed.

Minor comments:

Line 17: should read "Average concentrations of PM2.5 were 146 and 82 in winter and summer respectively." Line 25: "variation"->"variations" Line 110:"from"->"by" Line 189: delete "content" Line 201: "ratio"->"fraction" Line 315: "increasing" should read "increase" Line 321: EC and sulfate-> EC or sulfate Line 372: production->product

Interactive comment on Atmos. Chem. Phys. Discuss., https://doi.org/10.5194/acp-2018-83, 2018. 